\title{
Pre-treatment with cyclophosphamide or OX40 (CD134) costimulation targeting regulatory $T$ cell function enhances the anti-tumor immune effect of adoptively transferred $\mathrm{CD8}^{+} \mathrm{T}$ cells from wild-type mice
}

\author{
TOMOYUKI UEKI, SATOSHI MURATA, NAOMI KITAMURA, EIJI MEKATA and TOHRU TANI \\ Department of Surgery, Shiga University of Medical Science, Seta Tsukinowa, Otsu City, Shiga 520-2192, Japan
}

Received December 31, 2008; Accepted April 21, 2009

DOI: 10.3892/mmr_00000146

\begin{abstract}
Regulatory T cells (Tregs) are a major obstacle to the establishment of effective cancer immunotherapy. As mediators of immune tolerance, they are a critical target for pre-conditioning for adoptive immunotherapy. Here, we show that pre-treatment with cyclophosphamide or agonistic anti-OX40 mAb augments the anti-tumor immune effect of adoptive $\mathrm{CD}^{+} \mathrm{T}$ cell therapy in a clinically relevant wild-type model, as opposed to a TCR-transgenic mouse model. Tumor antigen-stimulated $\mathrm{CD}^{+} \mathrm{T}$ cells $\left(7 \times 10^{6}\right)$, including a small number $\left(2.17 \times 10^{5}\right)$ of tumor antigen-specific effector $\mathrm{CD}^{+}$ $\mathrm{T}$ cells, were transferred into tumor-bearing mice. A response was detected in the adoptively transferred antigen-specific $\mathrm{CD}^{+} \mathrm{T}$ cells, but was insufficient for the eradication of the established tumor. However, pre-treatment with cyclophosphamide to reduce Tregs was shown to enhance the anti-tumor immune effect of the adoptively transferred $\mathrm{CD} 8^{+} \mathrm{T}$ cells. Moreover, we demonstrated for the first time that pre-treatment with OX40 costimulation, with the aim of nullifying Tregmediated suppression, maintained the tumor-specific immune response of adoptively transferred $\mathrm{CD} 8^{+} \mathrm{T}$ cells, resulting in the eradication of the established tumor. These findings suggest that pre-conditioning with the aim of depleting Tregs is a useful strategy for adoptive cancer immunotherapy.
\end{abstract}

\section{Introduction}

Several strategies for immunotherapy have been evaluated in cancer patients; however, no consistent clinical response has been observed to date. One of the main reasons for this may be an immunological tolerance to tumor (self-) antigens. Tregs play a major role in tolerance to self-antigens. As tumorassociated antigens are derived from self-antigens, Tregs may be responsible for the observed lack of anti-tumor immune

Correspondence to: Dr Satoshi Murata, Department of Surgery, Shiga University of Medical Science, Seta Tsukinowa, Otsu City, Shiga 520-2192, Japan

E-mail: satoshi1@belle.shiga-med.ac.jp

Key words: murine model, $\mathrm{T}$ cells, costimulation, tumor immunity response (1). Indeed, their removal enhances anti-tumor immune response in animal models (1). Thus, one possible strategy for the successful immunotherapeutic treatment of cancer is the depletion of Tregs via pre-conditioning prior to immunotherapy.

Cyclophosphamide is an alkylating chemotherapeutic agent used to treat various types of cancer. Cyclophosphamide decreases the number of Tregs in tumor-bearing rats (2) and inhibits their suppressive abilities (3). Several pre-clinical studies have shown that low doses of cyclophosphamide enhance the anti-tumor activity of adoptively transferred T cells (4-6) or of tumor vaccines $(7,8)$.

OX40 (CD134) is a member of the TNF receptor family that is transiently expressed on effector $\mathrm{T}$ cells after $\mathrm{T}$ cell receptor (TCR) triggering. OX40 costimulation enhances the effector function, memory development and survival of $\mathrm{CD}^{+}$ or $\mathrm{CD}^{+} \mathrm{T}$ cells, resulting in the enhancement of anti-tumor immune effects in vivo (9-12). OX40 signaling inhibits the Treg-mediated suppression of effector $\mathrm{CD}^{+} \mathrm{T}$ cells without reducing the number of Tregs $(13,14)$, while the OX40mediated abrogation of Treg function boosts adoptive immune response and increases tumor rejection (15). However, little is known regarding the efficacy of pre-treatment using OX40 costimulation followed by adoptive $\mathrm{T}$ cell therapy on Tregmediated suppressive function.

Clonal $\mathrm{CD}^{+} \mathrm{T}$ cells isolated from tumor antigen-specific TCR-transgenic mice have generally been used in murine models of adoptive $\mathrm{T}$ cell therapy. This is because a number of tumor antigen-specific $\mathrm{T}$ cells can be obtained from these mice, and the response of the adoptively transferred $\mathrm{T}$ cells can easily be detected in the recipients, whereas from wild-type mice it is difficult to obtain a sufficient number of Ag-specific $\mathrm{CD}^{+}{ }^{+}$cells for the detection of immune effect. However, for the clinical application of new strategies for adoptive $\mathrm{T}$ cell therapy, an evaluation of anti-tumor immune effect using adoptively transferred $\mathrm{T}$ cells from wild-type animals is, if feasible, preferable. The present study evaluated the availability of antigen-specific $\mathrm{CD} 8^{+} \mathrm{T}$ cells from wild-type tumor-bearing mice for adoptive $\mathrm{T}$ cell therapy of an established tumor. The results revealed that pre-treatment with cyclophosphamide or OX40 costimulation to inhibit Treg-mediated suppressive function promoted the effector function of $\mathrm{CD} 8^{+} \mathrm{T}$ cells adoptively transferred from tumor-bearing wild-type mice, and 
resulted in the eradication of the established tumor in the recipient mice.

\section{Materials and methods}

Animals and cell lines. FVB/N mice were commercially obtained from The Jackson River Laboratory (USA). The animals were housed under pathogen-free conditions at the Shiga University of Medical Science, Japan. Experiments involving the use of the mice were performed in accordance with protocols approved by the Animal Care and Use Committee of Shiga University of Medical Science.

Non-transgenic (NT) cells were derived from the spontaneous mammary tumors of female HER2/neu transgenic mice as previously described (16). This NT cell line stably overexpresses rat HER2/neu cDNA. NT cells were grown in defined breast media and maintained at $37^{\circ} \mathrm{C}$ in $5 \% \mathrm{CO}_{2}$. NIH-3T3 cells were grown in $3 \mathrm{~T} 3$ media at $37^{\circ} \mathrm{C}$ in $10 \% \mathrm{CO}_{2}$. $3 \mathrm{~T} 3$ neu cells derived from NIH-3T3 cells overexpressing rat HER2/neu proto-oncogene were grown in 3T3 media with $0.3 \mu \mathrm{M}$ methotrexate at $37^{\circ} \mathrm{C}$ in $10 \% \mathrm{CO}_{2}$. The $3 \mathrm{~T} 3$ neu cells were genetically modified to express murine cytokine GM-CSF using retroviral vector MFG as previously described $(9,16,17)$, resulting in a 3T3-neu/GM cell line.

Antibodies and reagents. The $\mathrm{RNEU}_{420-429}$ (PDSLRDLSVF) and $\mathrm{NP}_{118-126}$ (RPQASGVYM) peptides ( $>95 \%$ purity) were synthesized and generously donated by the Oncology Peptide Synthesis Facility at Johns Hopkins University. Agonistic anti-OX40 mAb was produced from OX86 hybridoma cell lines. Purified rat IgG was used as a control Ab (Sigma). The antibodies were reconstituted in PBS, and were administered by i.p. injection at a dose of $300 \mu \mathrm{g}$ per mouse in $400 \mu \mathrm{l}$ PBS. APC anti-mouse CD8a, PE rat anti-mouse IFN- $\gamma$, FITC antimouse CD4 and PE anti-mouse CD25 were obtained from BD Pharmingen. APC-conjugated anti-mouse/rat Foxp3 and Foxp3 staining buffer sets were obtained from eBioscience. Image cytometry on sections (ICS) was performed as previously described (7) using a Cytofix/Cytoperm ${ }^{\text {TM }}$ Plus (with Golgistop $^{\mathrm{TM}}$ ) kit from BD Biosciences. Cyclophosphamide obtained from Sigma Chemical Co. was reconstituted in $400 \mu \mathrm{l}$ PBS, and administered by i.p. injection at a dose of $100 \mathrm{mg} / \mathrm{kg}$ body weight. $\mathrm{CD}^{+} \mathrm{T}$ cells were isolated from splenocytes and lymphocytes by magnetic separation using Dynabeads FlowComp ${ }^{\mathrm{TM}}$ mouse CD8 (Invitrogen). Cells were collected using the BD FACSCalibur flow cytometer (BD Biosciences). Data were analyzed using Cell Quest (BD Biosciences) and FlowJo (Tree Star Inc.) software.

Immunization of donor mice. Female FVB mice (6-8 weeks old) were injected s.c. with $5 \times 10^{6} \mathrm{NT} 2.5$ tumor cells in the mammary fat pad on day 3 , and with $3 \times 10^{6} 3 \mathrm{~T} 3 \mathrm{neu} / \mathrm{GM}$ vaccine cells divided equally between two forelimbs and one hind limb on day 0 . T cells were isolated from splenocytes and lymphocytes by nylon wool columns on day 7 . These cells were incubated at $37^{\circ} \mathrm{C}$ in $5 \% \mathrm{CO}_{2}$ for 2 days with $\mathrm{T}_{2} \mathrm{D}^{\mathrm{q}}$ cells pulsed with $\mathrm{RNEU}_{420-429}$ at a responder to stimulator ratio of 5:1. After 2 days of stimulation, the $\mathrm{CD}^{+} \mathrm{T}$ cells were isolated by magnetic separation using Dynabeads FlowComp mouse CD8. The purity of CD $8+\mathrm{T}$ cells was confirmed to be $>95 \%$.
Adoptive immunotherapy. The FVB recipient mice were injected s.c. with $5 \times 10^{6}$ NT2.5 tumor cells in the mammary fat pad on day 3, and i.p. with $100 \mathrm{mg} / \mathrm{kg}$ cyclophosphamide, $300 \mu \mathrm{g}$ anti-OX40 mAb or $300 \mu \mathrm{g}$ control IgG on day 2. Seven million HER2/neu-primed CD8 ${ }^{+} \mathrm{T}$ cells suspended in $400 \mu \mathrm{l}$ PBS were adoptively transferred into the recipient mice on day 0 . Splenocytes and lymphocytes were harvested from the recipient mice on day 6 , and ICS was performed. Tumor size was measured and recorded every 3 or 4 days according to the diameter along the orthogonal axes.

Population of $\mathrm{CD}^{+} \mathrm{CD}^{2} 5^{+} \mathrm{Foxp}^{+}$regulatory $\mathrm{T}$ cells in tumorinoculated mice following cyclophosphamide or anti-OX40 $m A b$ administration. FVB mice were injected s.c. with $5 \times 10^{6}$ NT2.5 tumor cells in the mammary fat pad on day 1, and i.p. with $100 \mathrm{mg} / \mathrm{kg}$ cyclophosphamide, $300 \mu \mathrm{g}$ anti-OX40 mAb or $300 \mu \mathrm{g}$ control IgG on day 0 . Splenocytes and lymphocytes were harvested, and red blood cells were lysed on days 0,2 , 4 and 6 . Subsequently, the population of $\mathrm{CD} 4{ }^{+} \mathrm{CD} 25^{+} \mathrm{Foxp} 3^{+}$ regulatory $\mathrm{T}$ cells was investigated using a flow cytometer.

Statistical analysis. Data analysis was performed using the Student's t-test.

\section{Results}

Generation and expansion of HER2/neu-specific CD8+ T cells for adoptive immunotherapy. As described above, for clinically relevant immunotherapy it is more relevant to use a wild-type mouse model than an antigen-specific TCR-transgenic mouse model when evaluating anti-tumor efficacy. However, these mice have a lower number of $\mathrm{Ag}$-specific $\mathrm{CD} 8^{+} \mathrm{T}$ cells, and in adoptive cytotoxic $\mathrm{T}$ lymphocyte (CTL) therapy for tumor eradication, the efficacy of the anti-tumor immune effect is dependent on the number of tumor-antigen-specific CTLs transferred; the greater the number of CTLs, the greater the efficacy. Consequently, antigen-specific $\mathrm{CD}^{+} \mathrm{T}$ cells were generated in vaccinated tumor-bearing wild-type mice and expanded with antigen-specific re-stimulation in vitro.

HER2/neu-specific CD8 ${ }^{+} \mathrm{T}$ cells, which were confirmed by IFN- $\gamma$-producing $\mathrm{CD}^{+} \mathrm{T}$ cell response to $\mathrm{RNEU}^{420-429}$, a HER2/neu immnodominant peptide (16), were generated in the tumor-bearing FVB/N wild-type mice treated with HER2/neutargeted vaccine $(16,17)$. T cells from these vaccinated FVB/N wild-type mice were re-stimulated with $\mathrm{T} 2 \mathrm{D}^{\mathrm{q}}$ cells pulsed with RNEU $_{420-429}$. Subsequently, the HER2/neu-specific CD8 ${ }^{+}$ $\mathrm{T}$ cells were expanded. The maximum frequency of HER2/ neu-specific $\mathrm{CD}^{+} \mathrm{T}$ cells was $3.14 \pm 0.276 \%$ on day 2 after re-stimulation in vitro (Fig. 1). Consequently, $\mathrm{CD} 8^{+} \mathrm{T}$ cells re-stimulated with $\mathrm{RNEU}_{420-429}$ for 2 days in vitro were used for the adoptive transfer experiments.

Persistence of effector function of adoptively transferred $C D 8^{+}$ $T$ cells with pre-conditioning for Treg depletion. A total of $7 \times 10^{6}$ in vitro re-stimulated $\mathrm{CD}^{+} \mathrm{T}$ cells from vaccinated wild-type $\mathrm{FVB} / \mathrm{N}$ mice were adoptively transferred into tumorbearing recipient $\mathrm{FVB} / \mathrm{N}$ mice with control rat-IgG. More HER2/neu-specific CD8 ${ }^{+} \mathrm{T}$ cells were detected in tumorbearing recipient mice with $\mathrm{T}$ cell transfer than in tumorbearing mice without $\mathrm{T}$ cell transfer (Fig. 2A), indicating that 


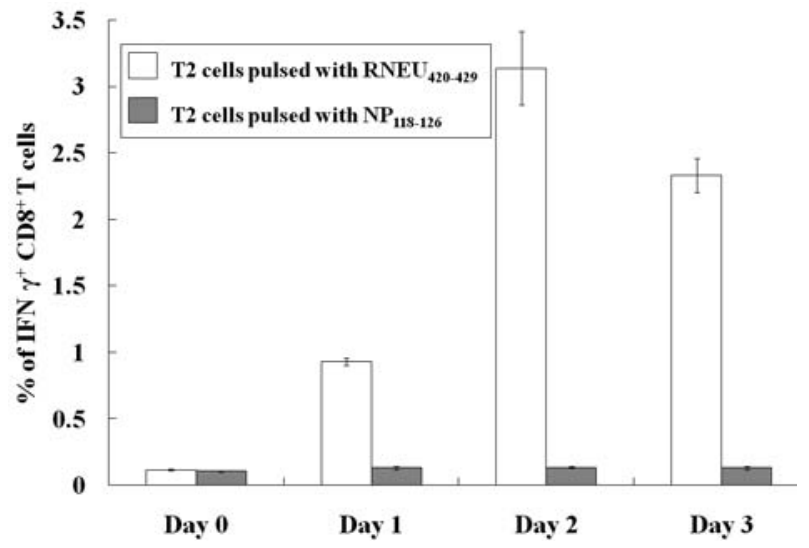

Figure 1. Isolated $\mathrm{T}$ cells from immunized mice were activated by the stimulation of $\mathrm{T}_{2} \mathrm{D}^{\mathrm{q}}$ cells pulsed with $\mathrm{RNEU}_{420-429}$. Representative data of three individual experiments are shown. There were three mice in each group. Error bars represent the SD of triplicate assays.

a small number $\left(\sim 2.17 \times 10^{5}\right.$ cells $)$ of HER2/neu-specific $\mathrm{CD} 8^{+}$ $\mathrm{T}$ cells persisted in an immune response to HER2/neu in the tumor-bearing recipients.

The recipient mice were pre-conditioned with cyclophosphamide or anti-OX40 mAb to inhibit the Treg-mediated suppression of $\mathrm{T}$ cells. Antigen-primed $\mathrm{CD} 8^{+} \mathrm{T}$ cells were transferred 2 days after pre-conditioning, and the persistence of antigen-specific $\mathrm{CD} 8^{+} \mathrm{T}$ cells was observed 6 days after the adoptive transfer of $\mathrm{CD}^{+} \mathrm{T}$ cells. $\mathrm{T}$ cell-transferred recipient mice pre-treated with cyclophosphamide administered i.p. retained significantly more HER2/neu-specific $\mathrm{CD}^{+} \mathrm{T}$ cells than the mice without pre-treatment (Fig. 2B). T celltransferred recipients pre-treated with anti-OX40 $\mathrm{mAb}$ administered i.p. also retained significantly more HER2/neuspecific $\mathrm{CD}^{+} \mathrm{T}$ cells than the mice without pre-treatment (Fig. 2C). Tumor-bearing mice treated with cyclophosphamide or anti-OX40 mAb did not generate HER2/neu-specific CD8+ T cells (Fig. 2B and C). This indicates that the frequency and function of a small number of adoptively transferred HER2/ neu-specific $\mathrm{CD}^{+} \mathrm{T}$ cell clones were maintained in vivo.

Enhanced anti-tumor immune effects of adoptively transferred HER2/neu-specific CD8 $8^{+}$cells with the pre-conditioning of Tregs in established tumor-bearing recipient mice. The antitumor efficacy of adoptive CTL therapy was examined in the tumor-bearing recipients with or without pre-treatment for the inhibition of Treg-mediated suppression. The recipient mice with adoptively transferred $\mathrm{CD} 8^{+} \mathrm{T}$ cells alone exhibited significantly delayed tumor growth in comparison to the mice without treatment ( $\operatorname{IgG}$ i.p. alone). However, alone the adoptively transferred $\mathrm{CD}^{+} \mathrm{T}$ cells were incapable of eliminating the tumors entirely (Fig. 3). Mice pre-treated with cyclophosphamide alone exhibited significantly inhibited tumor growth in comparison with the mice without pretreatment. In contrast, mice pre-treated with anti-OX40 mAb alone did not exhibit anti-tumor effects. This suggests that cyclophosphamide acts as an anti-tumor agent, while antiOX40 mAb has no anti-tumor efficacy on its own (Fig. 3). However, mice pre-treated with cyclophosphamide or anti$\mathrm{OX} 40 \mathrm{mAb}$ into which $\mathrm{CD} 8^{+} \mathrm{T}$ cells were then adoptively transferred demonstrated significantly inhibited tumor growth
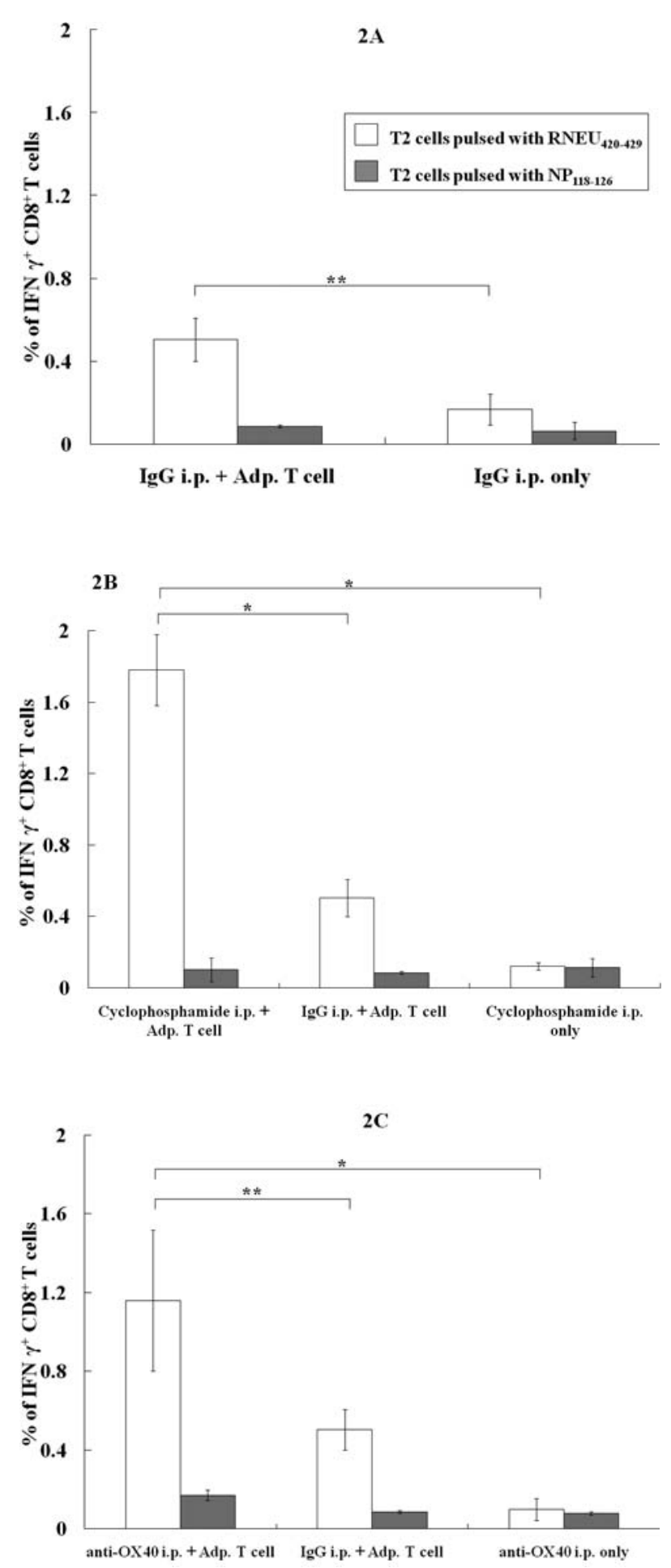

Figure 2. Pre-treatment with cyclophosphamide or anti-OX40 mAb augments the immune effects of adoptively transferred T cells. Representative data of three individual experiments are shown. There were three mice in each group. Significance was evaluated using the Student's t-test. ${ }^{*} \mathrm{P}<0.01 ;{ }^{* *} \mathrm{P}<0.05$.

in comparison to the mice that received the adoptive transfer of $\mathrm{CD}^{+} \mathrm{T}$ cells alone. In the cyclophosphamide or anti-OX40 $\mathrm{mAb}$ pre-treated mice, the established tumors were eventually completely eliminated (Fig. 3). Thus, pre-conditioning with cyclophosphamide or anti-OX40 mAb appears to synergistically enhance the function of a small number of tumor antigen specific CTLs from wild-type tumor-bearing hosts $\left(\sim 2.17 \times 10^{5}\right.$ cells $)$ to eradicate the established tumor. 


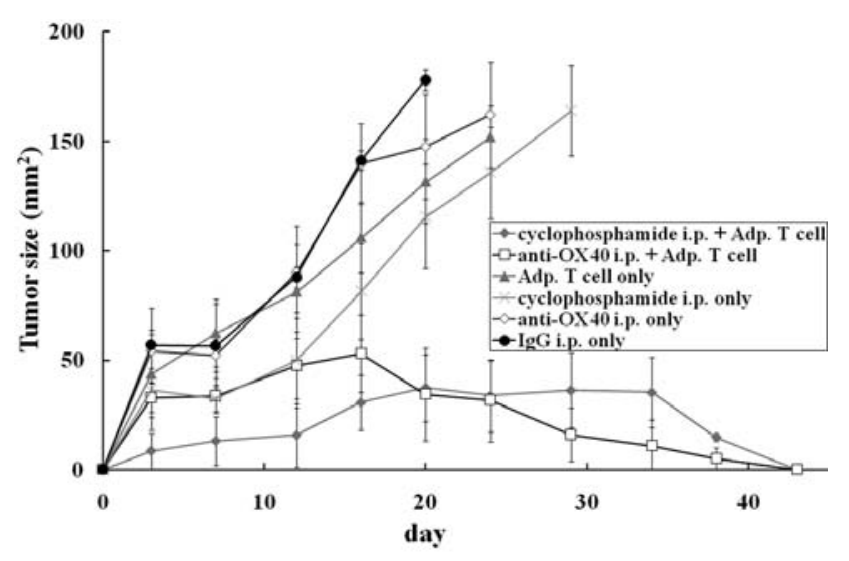

Figure 3. Adoptively transferred HER-2/neu-primed CD8 ${ }^{+} \mathrm{T}$ cells with cyclophosphamide or anti-OX40 mAb pre-treatment retard tumor growth. Representative data of three individual experiments are shown. The mean tumor size per group $(\mathrm{n}=3) \pm \mathrm{SD}$ is shown.

Frequency of Foxp3 $3^{+}$Tregs after cyclophosphamide or antiOX40 mAb administration. The number of Tregs after the administration of cyclophosphamide or anti-OX40 mAb was evaluated. The total number of lymphocytes was found to be decreased after cyclophosphamide administration, but remained constant after anti-OX40 $\mathrm{mAb}$ administration (Fig. 4A). The percentage of CD ${ }^{+} \mathrm{CD} 25^{+} \mathrm{Foxp} 3^{+}$Tregs in lymphocytes was constant after the administration of cyclophosphamide or anti-OX40 mAb (Fig. 4B). The number of $\mathrm{CD} 4{ }^{+} \mathrm{CD} 25^{+}{ }^{+}$oxp $3{ }^{+}$Tregs in lymphocytes from the spleen or lymph nodes showed a maximum decrease on day 2 after cyclophosphamide administration (Fig. 4C). In contrast, the number of $\mathrm{CD}^{+}{ }^{+} \mathrm{CD} 25^{+} \mathrm{Foxp} 3{ }^{+}$Tregs in lymphocytes was fixed after anti-OX40 mAb administration (Fig. 4C). However, though anti-OX40 mAb did not reduce the number of Tregs, it nonetheless appeared to inhibit Treg-mediated suppressive function.

\section{Discussion}

The results of the present study highlight two important findings related to adoptive immunotherapy. First, pretreatment with cyclophosphamide or anti-OX40 mAb targeting Tregs can maintain adoptively transferred tumor antigenspecific $\mathrm{CD}^{+}$cells in tumor-bearing mice, resulting in enhanced anti-tumor effects. Second, the eradication of established tumors can be obtained in vivo with the inhibition of Tregs by small numbers of adoptively transferred tumor antigen-specific $\mathrm{CD} 8^{+} \mathrm{T}$ cell clones from vaccinated tumorbearing wild-type mice, as opposed to the tumor antigenspecific TCR-transgenic mouse model commonly used. This suggests that $\mathrm{T}$ cell therapy with pre-conditioning is a potential clinically relevant form of immunotherapy.

Several strategies for immunotherapy in cancer patients have been evaluated; however, no significant clinical response has been observed to date. In mice, the depletion of immune cells by radiation or chemotherapy before adoptive $\mathrm{T}$ cell therapy can improve the anti-tumor efficacy of transferred $\mathrm{CD}^{+} \mathrm{T}$ cells (18). Several mechanisms might underlie the augmented efficacy of tumor-reactive $\mathrm{T}$ cells in the lymphopenic environment, including the elimination of immuno-
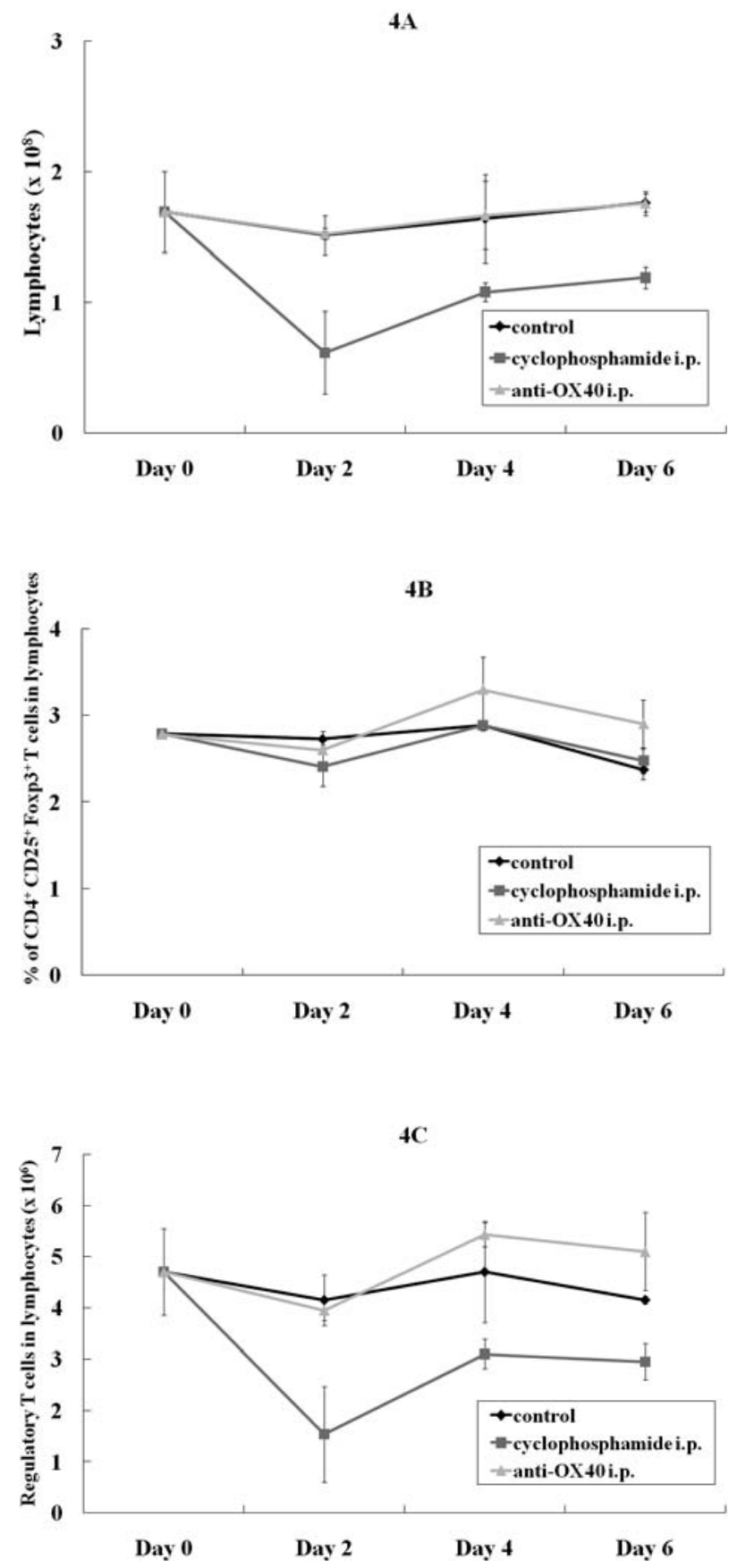

Figure 4. Effects of cyclophosphamide or anti-OX40 mAb administration on the number of Tregs. Representative data of three individual experiments are shown. There were three mice in each group. Error bars represent the SD of triplicate assays.

suppressive cells such as Tregs, the depletion of endogenous cells that compete for activating cytokines, and the increased function of antigen-presenting cells.

Tregs are crucial for the maintenance of peripheral selftolerance and for the suppression of anti-tumor response (19). The presence of Tregs may hinder the development of antitumor immune response following adoptive immunotherapy. Therefore, one possible strategy for augmenting adoptive $\mathrm{T}$ cell therapy may be to focus on the abrogation of the activity of the host Tregs prior to immunotherapy treatment. Several studies have shown that a low dose of cyclophosphamide can enhance the anti-tumor activity of adoptively transferred 
$\mathrm{T}$ cells. It has recently been demonstrated that cyclophosphamide decreases the number of Tregs while inhibiting their suppressive capability (20). In the current study, cyclophosphamide decreased both the number of lymphocytes and Foxp $3^{+}$Tregs. Under such lymphopenic conditions, residual nave $\mathrm{T}$ cells may proliferate and thus reconstitute a nearly normal lymphocyte pool, a process known as homeostatic proliferation (3). Tumor cells produce suppressive cytokines such as TGF- $\beta$, which directly expand pre-existing Tregs and convert nave $\mathrm{T}$ cells into Tregs. Thus, depleted Tregs can be replenished (15,21-24). Regarding the TCR repertoire, it is conceivable that any available antigens from normal tissues or pathogens beside tumor antigens could lead cognate lymphocytes to Treg cells through conversion, rather than to effector T cells. This allows the peripheral generation of Treg cells with a wide TCR repertoire, increasing their chances of encountering the antigen that activates their suppressive function (24). In the current study, a single administration of tumor antigen-specific $\mathrm{T}$ cells with the pre-treatment of cyclophosphamide was capable of eliminating a tiny established tumor that had been challenged 1 day before cyclophosphamide administration and 3 days before $\mathrm{T}$ cell transfer. In cases where repeated pre-conditioning by cyclophosphamide is required for an established larger tumor, the replenishment of Tregs with a wide TCR repertoire after their depletion might pose a problem.

Considering the replenishment of Tregs with a wide TCR following the depletion of Tregs, the functional inactivation of Tregs without $\mathrm{T}$ cell reduction would be an ideal strategy for Treg-targeted immunotherapy. OX40 triggering inhibits Treg-mediated suppressive functions (13-15), and OX40 costimulation reduces Foxp3 protein expression on Tregs. This reduced Foxp3 expression correlates with the abrogation of the Treg-mediated suppression of anti-tumor immunity (data not shown). In the present study, the number of lymphocytes and Tregs remained stable after OX40 costimulation (Fig. 4), and adoptively transferred HER2/neu-primed $\mathrm{CD}^{+} \mathrm{T}$ cells maintained their anti-tumor response in the mice pre-treated with anti-OX40 mAb. The finding that OX40 signaling on Tregs leads to their functional inactivation without a reduction in their numbers suggests that OX40 could augment the antitumor immune effects of adoptive $\mathrm{T}$ cell therapy without inciting the replenishment of Tregs. OX40 costimulation enhances OX40-expressing $\mathrm{CD}^{+}{ }^{+} \mathrm{T}$ cell function directly, as well as by means of $\mathrm{CD}^{+} \mathrm{T}$ cells (9). In the present experimental setting, in addition to the direct inhibition of Tregmediated suppression by OX40 costimulation, it is possible that OX40 signaling may have concomitantly increased a direct enhancement of adoptive $\mathrm{CD}^{+} \mathrm{T}$ cell function. Anti-OX40 $\mathrm{mAb}$ administered 2 days before $\mathrm{T}$ cell transfer might persist in its activity and may costimulate OX40-expressing effector $\mathrm{CD}^{+} \mathrm{T}$ cells activated by HER2/neu-peptide in vitro prior to the transfer. These unique functions of OX40 costimulation suggest a new strategy for adoptive $\mathrm{T}$ cell therapy targeting both Tregs and effector $\mathrm{T}$ cells by a sequence administration of anti-OX40 mAb before and after effector $\mathrm{T}$ cell transfer.

In general, large numbers of clonal $\mathrm{CD}^{+} \mathrm{T}$ cells isolated from antigen-specific TCR-transgenic mice are used for evaluating the effects of several types of murine adoptive immunotherapy. However, in human immunotherapy, it is difficult to obtain a large number of tumor antigen-specific CTLs, even if they are expanded by peptide-pulsed dendritic cells or anti-CD3 Ab. It is therefore important to develop an effective strategy to maintain and improve the function of the limited number of tumor antigen-specific $\mathrm{CD}^{+} \mathrm{T}$ cells that are adoptively transferred for anti-tumor immunotherapy. In the present study, adoptively transferred tumor antigen-specific CTLs alone had a very limited anti-tumor immune effect and did not succeed in eliminating the established tumors. However, pre-treatment with cyclophosphamide or antiOX40 mAb for the inhibition of Treg-mediated suppression maintained and improved the function of a small number of adoptively transferred antigen-specific $\mathrm{CD} 8^{+} \mathrm{T}$ cells from vaccinated tumor-bearing wild-type mice. These findings indicate that pre-conditioning with cyclophosphamide or anti-OX40 mAb for the inhibition of Treg-mediated suppression followed by adoptive $\mathrm{T}$ cell therapy synergistically enhances anti-tumor immune effects in a tumor-bearing host.

In conclusion, in this clinically relevant model using a small number of adoptively transferred CTLs from wild-type mice, a tumor antigen-specific response was detectable in recipient tumor-bearing mice. Pre-conditioning with cyclophosphamide or OX40 costimulation to inhibit regulatory $\mathrm{T}$ cell-mediated suppression synergistically enhanced the anti-tumor immune response of the CTLs. These combined treatments eradicated the established tumors, suggesting that pre-treatment targeting Tregs is useful for adoptive $\mathrm{T}$ cell immunotherapy.

\section{Acknowledgements}

We thank Dr Ishigaki and Mr. Ishida at the Department of Pathology for the valuable discussions. We also thank Mrs. Arikawa, Mrs. Ito and Mrs. Kamuro at the Department of Surgery for technical assistance, and Mr. Yamamoto and Mr. Mori at the Central Research Laboratory for technical support regarding the analysis of the flow cytometric data.

\section{References}

1. Shimizu J, Yamazaki S and Sakaguchi S: Induction of tumor immunity by removing $\mathrm{CD} 25^{+} \mathrm{CD} 4^{+} \mathrm{T}$ cells: a common basis between tumor immunity and autoimmunity. J Immunol 163: 5211-5218, 1999.

2. Ghiringhelli F, Larmonier N, Schmitt E, et al: $\mathrm{CD} 4{ }^{+} \mathrm{CD} 25^{+}$ regulatory $\mathrm{T}$ cells suppress tumor immunity but are sensitive to cyclophosphamide which allows immunotherapy of established tumors to be curative. Eur J Immunol 34: 336-344, 2004.

3. Bracci L, Moschella F, Sestili P, et al: Cyclophosphamide enhances the antitumor efficacy of adoptively transferred immune cells through the induction of cytokine expression, B-cell and T-cell homeostatic proliferation, and specific tumor infiltration. Clin Cancer Res 13: 644-653, 2007

4. Proietti E, Greco G, Garrone B, et al: Importance of cyclophosphamide-induced bystander effect on T cells for a successful tumor eradication in response to adoptive immunotherapy in mice. J Clin Invest 101: 429-441, 1998.

5. Gold JE, Zachary DT and Osband ME: Adoptive transfer of ex vivo-activated memory T-cell subsets with cyclophosphamide provides effective tumor-specific chemoimmunotherapy of advanced metastatic murine melanoma and carcinoma. Int J Cancer 61: 580-586, 1995.

6. Vierboom MP, Bos GM, Ooms M, Offringa R and Melief CJ: Cyclophosphamide enhances anti-tumor effect of wild-type p53-specific CTL. Int J Cancer 87: 253-260, 2000.

7. Ercolini EA, Ladle BH, Manning EA, et al: Recruitment of latent pools of high avidity $\mathrm{CD} 8^{+} \mathrm{T}$ cells to the antitumor immune response. J Exp Med 201: 1591-1602, 2005. 
8. Machiels JP, Reilly RT, Emens LA, et al: Cyclophosphamide, doxorubicin, and paclitaxel enhance the antitumor immune response of granulocyte/macrophage-colony stimulating factorsecreting whole-cell vaccines in HER-2/neu tolerized mice. Cancer Res 61: 3689-3697, 2001.

9. Murata S, Ladle BH, Kim PS, et al: OX40 costimulation synergizes with GM-CSF whole-cell vaccination to overcome established $\mathrm{CD} 8^{+} \mathrm{T}$ cell tolerance to an endogenous tumor antigen. J Immunol 176: 974-983, 2006.

10. Gramaglia I, Weinberg AD, Lemon M and Croft M: OX40 ligand: a potent costimulatory molecule for sustaining primary CD4 T cell responses. J Immunol 161: 6510-6517, 1998.

11. Song J, So T, Cheng M, Tang X and Croft M: Sustained surviving expression from $\mathrm{OX} 40$ costimulatory signals drives $\mathrm{T}$ cell clonal expansion. Immunity 22: 621-631, 2005.

12. Rogers PR, Song J, Gramaglia I, Killeen N and Croft M: OX40 promotes $\mathrm{Bcl}-\mathrm{x}_{\mathrm{L}}$ and $\mathrm{Bcl}-2$ expansion and is essential for longterm survival of CD4 T cells. Immunity 15: 445-455, 2001.

13. Valzasina B, Guiducci C, Dislich H, et al: Triggering of OX40 (CD134) on $\mathrm{CD}^{+} \mathrm{CD} 25^{+} \mathrm{T}$ cells blocks their inhibitory activity: a novel regulatory role for OX40 and its comparison with GITR. Blood 105: 2845-2851, 2005.

14. Vu MD, Xiao X, Gao W, et al: OX40 costimulation turns off Foxp3 ${ }^{+}$Tregs. Blood 110: 2501-2510, 2007.

15. Piconese S, Valzasina B and Colombo MP: OX40 triggering blocks suppression by regulatory $\mathrm{T}$ cells and facilitates tumor rejection. J Exp Med 205: 825-839, 2008.

16. Ercolini AM, Machiels JP, Chen YC, et al: Identification and characterization of the immunodominant rat HER-2/neu MHC class I epitope presented by spontaneous mammary tumors from HER-2/neu-transgenic mice. J Immunol 170: 4273-4280, 2003.
17. Reilly RT, Gottlieb MB, Ercilini AM, et al: HER-2/neu is a tumor rejection target in tolerized HER-2/neu transgenic mice. Cancer Res 60: 3569-3576, 2000.

18. Gattinoni L, Powell DJ Jr, Rosenberg SA and Restifo NP: Adoptive immunotherapy for cancer: building on success. Nat Rev Immunol 6: 383-393, 2006.

19. Sakaguchi S: Naturally arising Foxp3-expressing CD $25^{+} \mathrm{CD} 4{ }^{+}$ regulatory $\mathrm{T}$ cells in immunological tolerance to self and nonself. Nat Immunol 6: 345-352, 2005.

20. Lutsiak ME, Semnani RT, De Pascalis R, Kashmiri SV, Schlom J and Sabzevari H: Inhibition of CD4(+)CD25(+) T regulatory cell function implicated in enhanced immune response by low-dose cyclophosphamide. Blood 105: 2862-2868, 2005.

21. Zhou G, Drake CG and Levitsky HI: Amplification of tumorspecific regulatory $\mathrm{T}$ cells following therapeutic cancer vaccines. Blood 107: 628-636, 2006.

22. Zhou G and Levitsky HI: Natural regulatory T cells and de novoinduced regulatory $\mathrm{T}$ cells contribute independently to tumorspecific tolerance. J Immunol 178: 2155-2162, 2007.

23. Liu VC, Wong LY, Jang T, et al: Tumor evasion of the immune system by converting $\mathrm{CD} 4^{+} \mathrm{CD} 25^{+} \mathrm{T}$ cells into $\mathrm{CD} 4^{+} \mathrm{CD} 25^{+} \mathrm{T}$ regulatory cells: role of tumor-derived TGF- 3 . J Immunol 178: 2883-2892, 2007.

24. Colombo MP and Piconese S: Regulatory-T-cell inhibition versus depletion: the right choice in cancer immunotherapy. Nat Rev Cancer 7: 880-887, 2007. 